Article

\title{
Functional Identification of $P x$-fringe and $P x$-engrailed Genes under Heat Stress in Chlorpyrifos-Resistant and -Susceptible Plutela xylostella (Lepidoptera: Plutellidae)
}

\author{
Yu Wang ${ }^{1,2}$, Jingnan Wang ${ }^{1,2}$, Xiaofeng $\mathrm{Xia}^{1,2, *}$ and Gang $\mathrm{Wu}^{1,2, *}$ \\ 1 Key Laboratory of Biopesticide and Chemical Biology (Ministry of Education), Fujian Agriculture and \\ Forestry University, Fuzhou 350002, China; W1823301539@outlook.com (Y.W.); wjn5663@163.com (J.W.) \\ 2 State Key Laboratory of Ecological Pest Control for Fujian and Taiwan Crops, Institute of Applied Ecology, \\ Fujian Agriculture and Forestry University, Fuzhou 350002, China \\ * Correspondence: xiaofengxia@fafu.edu.cn (X.X.); newugan@163.com (G.W.)
}

Received: 11 February 2020; Accepted: 21 March 2020; Published: 7 May 2020

\begin{abstract}
In our previous research, the fitness cost of resistance of the diamondback moth (DBM), Plutella xylostella found in insecticide-resistant DBM (Rc-DBM) under heat stress was based on heavier damage to wing veins when compared to insecticide-susceptible DBM (Sm-DBM). To investigate the molecular mechanism of the damage to the veins between Rc- and Sm-DBM, the full-length sequences of two related genes involved in the development of wing veins, fringe ( $P x-f n g)$ and engrailed $(P x-e n)$ of DBM were cloned, and the mRNA expressions of both $P x$-fng and $P x$-en were studied. The $P x$-fng and $P x$-en cDNA contained $1038 \mathrm{bp}$ and $1152 \mathrm{bp}$ of open reading frames (ORFs), respectively, which encoded a putative protein comprising 345 and 383 amino acids with a calculated molecular weight of $39.59 \mathrm{kDa}$ and $42.69 \mathrm{kDa}$. Significantly down regulated expressions of $P x$-fng and $P x$-en under heat stress were found in pupae and adults of Rc-DBM compared to Sm-DBM, and a result of higher damage to wing veins in Rc-DBM under heat stress. Based on RNAi experiments, significant inhibitions on expressions of $P x-f n g$ and $P x$-en in both Sm-DBM and Rc-DBM were found when the pupae were infected by dsFng or dsEn. Corresponding to these, infections of dsFng or dsEn resulted in significant decrease of eclosion rate and increase malformation rate of DBM. Our results suggest that the higher damage of wing veins in DBM might be related to the heavier inhibitions of $P x-f n g$ and $P x$-en expression, and the $P x$-fng and $P x$-en are involved in the development of wings and veins.
\end{abstract}

Keywords: fringe; engrailed; resistant and susceptible Plutella xylostella; heat stress

\section{Introduction}

Wings, as crucial organs for insects to resist survival stress and cope with damage, are comprised of axilla, veins, membrane, fold lines, flexion lines, and surface structures [1]. The veins serve as the skeleton for the wings and are the primary supporting structure composed of nerves, hemolymphs, and trachea [1].The development of wings is composed of three cascade signaling pathways: proximal-distal (P-D); dorsal-ventral (D-V); and anterior-posterior (A-P) [2]. The relevant genes in the three cascade signaling pathways such as engrailed (en), apterous (ap), arista-less, etc. determine the differentiation of the wing disc [3,4].It has also been reported that temperature affects the development of insect wings, for example, the sizes and shapes of wings are affected by temperature in Drosophila [5] and P. xylostella [6].

The gene regulatory pathway in insect wing vein development has mainly been carried out in Drosophila [2,7-9]. Engrailed is a nuclear regulatory protein that plays an essential role in wing 
morphogenesis [10] and has dual distinct functions in the development of the wing disc [11].It is known that the engrailed gene is correlated with the posterior cell compartment. Furthermore, engrailed selective expression determines the differentiation of the anterior-posterior (A-P) boundary during the whole wing development $[10,12,13]$. Engrailed interacts with some other proteins and could be post-translationally manipulated to increase the level of genetic diversity [14,15]. Moreover, for some insects, Engrailed-family genes function as a switch to regulate the wing color patterns [16]. Fringe was first discovered because it plays a critical role in locating Notch activation of special boundary cells along the dorsal ventral septal boundary of the wings [17].It is well known that fringe is a glycosyltransferase, which is located in the Golgi and plays a part in the Notch [18].Fringe-modulated deployment of Notch signaling is important to the boundary formation of wings [19].Fringe protein encodes a boundary-specific cellular signaling molecule that is responsible for the interaction between dorsal-abdominal cells during wing development [17]. It has been reported that the loss of fringe expression could lead to an abnormal development of wings boundary, and can even result in wing loss $[17,20]$.

In addition to the studies on Drosophila, there have also been some studies on the development of venation in other insects in recent years. A pupa-specific expression of chitin synthase A $2 b$ (CHSA-2b) in Bombyx mori was identified. This protein was expressed in the wing in mid-pupal stage and regulates the wing development [21,22]. The hormone 20-hydroxyecdysone (20E) regulates the expression of CHSA-2 $b$ to mediate the wing formation $[21,22]$. $\beta-\mathrm{N}$-acetylglucosaminidases (NAGs) is a group of enzymes that degrade chitino ligosaccharides, which is important for insect development and metamorphosis in Lasioderma serricorne. Knockdown of $\beta-\mathrm{N}$-acetylglucosaminidase 2 decreased many other wing-development-related genes, thus affecting the molting and wing development [23]. In the brown planthopper (BPH) Nilaparvata lugens, knockdown of the decapentaplegic (dpp) gene causes different phenotypes in the long-winged (LW) and short-winged (SW) morphs, but both cause the absence of wing veins and affect the wing morph transformation [24]. Earlier studies have also revealed that dpp is closely related to the development of the wings and veins of Drosophila [25]. The directional transport of dpp may generate diversified patterns of insect wing vein [26]. Similarly, in the sawfly Athalia rosae, the decapentaplegic (dpp)/bone morphogenetic protein (BMP) signal pathway plays an important role in the development of the wing vein. The dpp transport system and the spatial transcription factors of the BMP significantly affect the development of wings and veins $[27,28]$.

DBM is a global economic pest that feeds on cruciferous crops. Meanwhile, DBM has developed resistance to several insecticides [29-32]. In our previous study, heat stress can affect the fitness cost of resistant DBM. Compared to chlorpyrifos-susceptible DBM, chlorpyrifos-resistant DBM has a significantly lower fertility, thermal tolerance, heat shock protein expression, but higher germ and ovary cell damage, and an upregulating expression of mitochondrial apoptosis-related genes (caspase-9, Apaf-1b, cytochrome c) [6,33-35]. The results indicated that Rc-DBM showed significant fitness cost caused by insecticide resistance. Under insecticide screening, the ability of insects to resist environmental stress decreased to a certain extent, which was the fitness cost. The fitness cost refers to the ability of insects to adapt to survive in the natural environment and pass this trait to the next generation through genes, which generally include fecundity and viability [36]. We also found that nine genes in chlorpyrifos-resistant DBM, which were thought to be involved in wing development in Drosophila [2], had a significant downregulated expression under heat stress when compared to chlorpyrifos-susceptible DBM [37]. Although significantly down regulated expressions of the nine genes under heat stress [37] and vein damage were found under heat stress in Rc-DBM [6], it was unclear if the nine genes were involved in the wing development of DBM. As fringe (fng) and engrailed (en) are thought to be wing-development-related genes [2], in this study, fringe ( $P x-f n g)$ and engrailed $(P x-e n)$ were identified, and the mRNA dynamic expressions of $P x$-fng and $P x$-en were investigated in chlorpyrifos-resistant and -susceptible DBM under heat stress. In addition, the function of the two genes in the wing development of DBM was confirmed by using RNA interference (RNAi). 


\section{Materials and Methods}

\subsection{Source of Insect}

Chlorpyrifos-resistant $(\mathrm{Rc})$ and -susceptible $(\mathrm{Sm})$ strains of DBM were kept in our laboratory for a long time. The information about the two strains of DBM was described in detail in our previous study [34].

\subsection{Cloning of Fringe (Px-fng) and Engrailed (Px-en) Genes}

Sample: fringe and engrailed gene in DBM were named as $P x$-fng and $P x$-en in this study, respectively. For cloning fing and en, fourth instar larvae from Sm-DBM were collected and reared at $25^{\circ} \mathrm{C}$ and $80 \%$ relative humidity $(\mathrm{RH})$ with a 16:8 h light/dark (L:D) photoperiod in an environmental chamber. The F1 progenies of the pupae and adults were used for the total RNA extraction.

\subsection{Amplification of the Initial Fragments of Fringe (Px-fng) and Engrailed (Px-en)}

The MiniBEST Universal RNA Extraction Kit (TaKaRa Bio Inc., Dalian, China) was used to extract total RNA from different samples. We compared the fng and en sequences in NCBI with other insects to find the conservative regions of cDNA and tried to design primers using Primer Premier 5.0 (Table 1).The polymerase chain reaction (PCR) system was $50 \mu \mathrm{L}$, the optimum reaction system of PCR wasTaKaRaExTaq0.25 $\mu \mathrm{L}, 10 \times$ ExTaq Buffer $5.0 \mu \mathrm{L}$, dNTP Mixture4.0 $\mu \mathrm{L}$, Template $1.0 \mu \mathrm{L}$, Primer $11.0 \mu \mathrm{L}$, Primer $21.0 \mu \mathrm{L}$, and $\mathrm{ddH}_{2} \mathrm{O} 37.75 \mu \mathrm{L}$. We used a 2720 Thermal Cycle for this PCR reaction. The PCR condition was: $95^{\circ} \mathrm{C}$ denaturation for $3 \mathrm{~min}$, followed by 35 cycles of $94{ }^{\circ} \mathrm{C} 30 \mathrm{~s}, 59.9^{\circ} \mathrm{C}$ $1 \mathrm{~min}$ for $P x$-fng, or $57.8^{\circ} \mathrm{C} 1 \mathrm{~min}$ for $P x$-en, then extension at $72{ }^{\circ} \mathrm{C}$ for $1 \mathrm{~min}$, and $72{ }^{\circ} \mathrm{C} 10 \mathrm{~min}$ for the final reaction. PCR products were detected by electrophoresis on $1 \%$ agarose gel. The specific DNA fragments were purified with the MiniBEST agarose gel DNA Extraction Kit. Then, it was connected to a pMD20-T vector and finally transfected into competent cells. The bacterial solution was sent to be sequenced by Fuzhou Boshang Biotechnology Co. Ltd.

Table 1. Primers used for cloning fringe ( $P x-f n g)$ and engrailed (Px-en) genes of the diamondback moth (DBM).

\begin{tabular}{|c|c|c|c|c|}
\hline Names of Primers & & Sequences of Primers $\left(5^{\prime}-3^{\prime}\right)$ & $\operatorname{Tm}^{\circ} \mathrm{C}$ & Isolated Gene \\
\hline \multicolumn{5}{|c|}{ For initial fragment(s) } \\
\hline en-1F & & 5' CCGTGATAAACCCAGTCCAA 3' & 57.8 & Px-en-1-1 \\
\hline en-1R & & 5’ GCTTTCAGTGGCTGTCGTGT 3' & 59.9 & \\
\hline fng- $1 F$ & & $5^{\prime}$ TTCCTGGTTTATCAAGGTGG $3^{\prime}$ & 55.8 & Px-fng-2-1 \\
\hline fng-1R & & $5^{\prime}$ AATACAGTCATGTCGCTCAA 3' & 53.7 & \\
\hline \multicolumn{5}{|l|}{ For RACE } \\
\hline en-3-1 & & $5^{\prime}$ TTGGAGGGTTGAGGCAGACG 3' & 61.9 & Px-en-3-1 \\
\hline en-3-2 & & 5' CCTGTTTGCGTTATTGTCACG 3' & 61.9 & \\
\hline en-5-1 & & 5' TGCCTCAACCСТCCAAGCGG 3' & 64 & Px-en-5-1 \\
\hline en-5-2 & & $5^{\prime}$ GGTCGTATGGCTTGTAAAGAAT 3' & 56.3 & \\
\hline fng-3-1 & & $5^{\prime}$ GCAAAACAGAAAGGGACGGA $3^{\prime}$ & 57.8 & Px-fng-3-1 \\
\hline fng-3-2 & & 5' TGAGACGGAAAGCGGCGAGG 3' & 64 & \\
\hline fng-5-1 & & $5^{\prime}$ TGAAGCGGGTTGTCTATGTCCGTG 3' & 63.7 & Px-fng-5-1 \\
\hline \multirow[t]{2}{*}{ fng-5-2 } & & $5^{\prime}$ TGATACTGATGAAGCGGGTTGTC $3^{\prime}$ & 60.2 & \\
\hline & & 5'CTAATACGACTCACTATAGGGCAAG & & \\
\hline \multirow[t]{2}{*}{ UPM } & $\mathrm{L}^{*}$ & CAGTGGTATCAACGCAGAGT3' & & \\
\hline & $S^{*}$ & 5'CTAATACGACTCACTATAGGGC3' & & \\
\hline \multicolumn{5}{|c|}{ с } \\
\hline fng-C-1F & & $5^{\prime}$ ATGAAAGGGCTAAGCAGAAT 3' & 53.7 & \\
\hline fng-C-1R & & $5^{\prime}$ ACAAAACAGGGAATCAACAT 3' & 51.7 & \\
\hline en-C-1F & & $5^{\prime}$ CCACGGCATACATTATCATC $3^{\prime}$ & 55.8 & \\
\hline en-C-1R & & $5^{\prime}$ GCCTCTACCCATTACAACAA $3^{\prime}$ & 55.8 & \\
\hline
\end{tabular}

\subsection{Rapid Amplification of cDNA Ends (RACE) of Fringe (Px-fng) and Engrailed (Px-en)}

The SMARTer ${ }^{\circledR}$ RACE 5'/3' Kit (Clontech Laboratories, Inc., Mountain View, USA) was used to clone the $3^{\prime}$ - and $5^{\prime}$-cDNA sequences of $P x$-fng and Px-en. The total volume of the PCR system was 
$50 \mu \mathrm{L}$, the optimum reaction system of PCR was Ex-Taq (5 U/ $\mu \mathrm{L}) 0.25 \mu \mathrm{L}$, dNTP-Mix $(2.5 \mathrm{mM}) 4.0 \mu \mathrm{L}$, 5'-or 3'-RACE-Ready cDNA $3.0 \mu \mathrm{L}, 5^{\prime}$ or 3' GSP $(10 \mu \mathrm{m}) 1.0 \mu \mathrm{L}, 10 \times$ UPM $1.0 \mu \mathrm{L}, 10 \times$ Ex-Taq Buffer $5.0 \mu \mathrm{L}$, and $\mathrm{ddH}_{2} \mathrm{O} 35.75 \mu \mathrm{L}$, based on the intermediate sequences we have previously cloned (Table 2 ). The PCR condition was: $94{ }^{\circ} \mathrm{C} 3 \mathrm{~min}, 94^{\circ} \mathrm{C} 30 \mathrm{~s}, 68^{\circ} \mathrm{C} 30 \mathrm{~s}, 72{ }^{\circ} \mathrm{C} 3 \mathrm{~min}, 25$ cycles, $72{ }^{\circ} \mathrm{C} 7 \mathrm{~min}$.

Table 2. Primers used for qPCR identification of $P x-f n g$ and Px-en in DBM.

\begin{tabular}{cccc}
\hline Primers & Sequences of Primers $\left(5^{\prime}-\mathbf{3}^{\prime}\right)$ & Gene Names & Product Size(bp) \\
\hline$\beta$-actin-F & 5'CCGAGAGAGAAATCGTGCGT 3' & \multirow{2}{*}{ 3-actin } & 110 \\
$\beta$-actin-R & 5'GTAGGACTTCTCGAGCGAGC 3' & \\
Ef-F & 5'AGATGCACCACGAAGCTCTC 3' & Px-ef & 118 \\
Ef-R & 5'TTGTTCTTGGAGTCTCCGGC 3' & & 135 \\
Px-fng-q-F & 5'CGGACATAGACAACCCGCTT 3' & Px-fng & 112 \\
Px-fng-q-R & 5'TCCCGCTGTTGATGAAGTGG 3' & & \\
Px-en-q-F & 5'CGCGGAGAATCTCATGAGCT 3' & Px-en & \\
Px-en-q-R & 5'TGGCTGGACCTTCACAATGG 3' & & \\
\hline
\end{tabular}

\subsection{Amplification of open Reading Frames (ORFs)}

The previous three sequencing results were spliced to obtain the full cDNA sequences. Using the NCBI online ORF Finder (http://www.ncbi.nlm.nih.gov/gorf/gorf.html) to identify the ORFs. In order to verify the accuracy of full-length gene splicing and eliminate the problem of inaccurate tail sequence in the process of sequence splicing, specific primers were designed at both ends to amplify the ORF sequences, respectively (Table 1). PCR conditions was: The total volume of the PCR system was the same as the amplification of the initial fragments, $94{ }^{\circ} \mathrm{C} 5 \mathrm{~min}$, followed by 35 cycles at $94{ }^{\circ} \mathrm{C}$ $30 \mathrm{~s}$, annealing at $52^{\circ} \mathrm{C} 30 \mathrm{~s}$ for $P x-f n g, 55^{\circ} \mathrm{C} 30 \mathrm{~s}$ for $P x$-en, extension at $72{ }^{\circ} \mathrm{C} 2 \mathrm{~min}$, with final reaction of $72{ }^{\circ} \mathrm{C} 8 \mathrm{~min}$.

\subsection{Real-Time Quantitative Polymerase Chain Reaction (qPCR)}

\subsubsection{Temperature Shock}

In this experiment, adults or pupae of Rc- or Sm-DBM were treated with heat stress. The high temperature treatment mimicked the field micro-climate temperature in Fuzhou in summer [6]. The temperature treatment was divided into four groups based on our previous study [6], the control group was treated at $25^{\circ} \mathrm{C}$ for different times, and the corresponding experimental group was treated at different temperatures: Group (1): $25{ }^{\circ} \mathrm{C}$ for $1 \mathrm{~h}$ as the control group, $44^{\circ} \mathrm{C}$ for $1 \mathrm{~h}$ as the treatment group; Group (2): $25{ }^{\circ} \mathrm{C}$ for $4 \mathrm{~h}$ as the control group, $42{ }^{\circ} \mathrm{C}$ for $4 \mathrm{~h}$ and 8 has the treatment group; Group (3): $25^{\circ} \mathrm{C}$ for 8 has the control group, $40{ }^{\circ} \mathrm{C}$ for $8 \mathrm{~h}$ and 16 has the treatment group; and Group (4): $25{ }^{\circ} \mathrm{C}$ for 48 has the control group, $38^{\circ} \mathrm{C}$ for 48 has the treatment group. Before the total RNA extraction, the high-temperature treated DBM should recover at $25^{\circ} \mathrm{C}$ for $1 \mathrm{~h}$.

\subsubsection{Determination of mRNA Expression}

We used the SYBR ${ }^{\circledR}$ GREEN (Takara, Dalian, China) fluorescent method in the 7500 Fast RealTime PCR System to complete the determination of $P x$-fng and $P x$-en expression quantity. All the experimental samples under went three biological repeats (with ten insect individuals for each replication) and three technical repeats for each temperature treatment. Primers for quantitative fluorescence PCR were designed by the primer premier 5.0 (Table 2). Meanwhile, $\beta$-actin and Elongation factor (Ef) were used as the house-keeping genes. The total volume of the PCR system was $20 \mu \mathrm{L}$, the optimum reaction system of PCR was $5 \times$ PrimeScript Buffer $4.0 \mu \mathrm{L}$, PrimeScript RT Enzyme Mix I $1.0 \mu \mathrm{L}$, Oligo dT Primer $(50 \mu \mathrm{M}) 1.0 \mu \mathrm{L}$, Random 6 mers $(100 \mu \mathrm{M}) 1.0 \mu \mathrm{L}$, Total RNase Free $\mathrm{ddH}_{2} \mathrm{O}$ up to $13.0 \mu \mathrm{L}$. PCR conditions was: $95^{\circ} \mathrm{C} 30 \mathrm{~s}, 95^{\circ} \mathrm{C} 5 \mathrm{~s}, 60^{\circ} \mathrm{C} 34 \mathrm{~s}, 40$ cycles in total. The experimental data were obtained and analyzed using the $2^{-\Delta \Delta \mathrm{Ct}}$ method. 


\subsection{Functional Analysis of Px-fng and Px-en on Deformities and Damage in DBM Wings by RNAi}

To explore the effects of $P x$-fng and $P x$-en in DBM wing development, RNAi was used to silence the expression of $P x-f n g$ and $P x$-en. Based on the entire coding sequence of $P x$-fng and $P x$-en, the double stranded RNA (dsRNA) and qPCR primers were designed (Table 3). Meanwhile, the dsGFP was synthesized as a negative control (Table 3) [38]. As vein differentiation in a wing disc occurs at the pupae stage, pupae were used for the RNAi experiments. The pupae were divided into four groups. In each group, seventy pupae were injected with $69 \mathrm{~nL}$ and $138 \mathrm{~nL}(2 \mu \mathrm{g} / \mu \mathrm{L})$, dsGFP, dsFng, and dsEn using Nanoliter 2000/B203XVB (WPI) at $25^{\circ} \mathrm{C}$ for $4 \mathrm{~h}, 8 \mathrm{~h}, 16 \mathrm{~h}$, and $48 \mathrm{~h}$, respectively. According to the survival rate and the effect of RNAi, the injection amount of each pupa was determined to be $138 \mathrm{nl}$ dsRNA in each insect (Table 4). The hind wings of emerged adults were collected and the wing scales were gently rinsed out with $70 \%$ ethanol to make the veins appear more clearly [6]. Then, they were observed by zoom stereoscopic microscope (Nicon SMZ18, Tokyo, Japan). The wing deformity was assumed to occur when different sizes and shapes of the wings were found compared to the normal wings. The degree of wing damage was determined by the two hind wings of each adult, because damage may occur on one or both hind wings of an adult. In addition, since damage may occur on one or both hind wings of any adult, vein damage is considered to occur when the radinus posterior (Rp) vein disappears [6]. Three biological replications were performed with 70 individual insects for each replication in the observations on the effects of RNAi on the wing morphology of DBM. Six individuals among them were used in the expression analysis of mRNA.

Table 3. Primer sequences for dsRNA amplification and qPCR.

\begin{tabular}{|c|c|}
\hline Primers for PCR & Sequences of Primers $\left(5^{\prime}-3^{\prime}\right)$ \\
\hline \multicolumn{2}{|l|}{ Primers for dsRNA Amplification } \\
\hline dsFng-F & 5'TAATACGACTCACTATAGGGCTTGGCATGAAAGGGCTAAG3' \\
\hline dsFng-R & 5'TAATACGACTCACTATAGGGTGAAGTGGTCGTACTCGACG3' \\
\hline dsEn-F & 5'TAATACGACTCACTATAGGGCCGAGGTATGAGAGGAACCA3' \\
\hline dsEn-R & 5'TAATACGACTCACTATAGGGTTCTGAACCTCCCCAATCTG3' \\
\hline \multicolumn{2}{|l|}{ Primers for qPCR } \\
\hline RT-qPCR dsFng-F & 5'GTAGGTCGCTACGGCAAAGT3' \\
\hline RT-qPCR dsFng-R & 5'CACGTTCCGTCCCTTTCTGT3' \\
\hline RT-qPCR dsEn-F & 5'ATCGATGACGCGACGATTCA3' \\
\hline RT-gPCR dsEn-R & 5'AACACACACAACGGCGATTG3' \\
\hline dsGFP-F & 5'TAATACGACTCACTATAGGGCAGTGCTTCAGCCGCTAC3' \\
\hline dsGFP-R & 5'TAATACGACTCACTATAGGGGTTCACCTTGATGCCGTTC3'- \\
\hline
\end{tabular}

Table 4. Statistics on the emergence and wing deformity when dsFng and dsEn were injected.

\begin{tabular}{cccc}
\hline Genes Injected & Numbers Tested & Emergence (Mean \pm SE) (\%) & Deformity (Mean \pm SE) (\%) \\
\hline dsFng & 210 & $71.9 \pm 2.65 \mathrm{~b}$ & $37.9 \pm 2.76 \mathrm{~b}$ \\
dsEn & 210 & $72.85 \pm 2.85 \mathrm{~b}$ & $40.6 \pm 3.38 \mathrm{~b}$ \\
dsGFP & 210 & $94.28 \pm 1.64 \mathrm{a}$ & $0 \mathrm{a}$ \\
dsH2O & 210 & $90.95 \pm 1.25 \mathrm{a}$ & $0 \mathrm{a}$ \\
\hline
\end{tabular}

Note: $138 \mathrm{nl}$ dsFng, dsEn, dsGFP, or $\mathrm{ddH}_{2} \mathrm{O}$ was injected to each pupa, respectively. Different lowercase letters in each volume indicate significant differences in each treatment (Duncan's test, $p \leq 0.05$ ).

\subsection{Multiple Sequence Alignment and Phylogenetic Analysis}

For the multiple sequence alignment of $P x$-fng and $P x$-En, the deduced amino acid sequences of $P x-f n g / P x-E n$, and the related sequences (Fringe/Engrailed) known in other species were aligned by DNAMAN V6, respectively. For the phylogenetic analysis, the amino acid sequences of Fringe/Engrailed of other insects were downloaded from the NCBI database, and their homologous sequences, brainiac and invected, were downloaded, respectively. The ClustalW program in MEGA6.0 [39] was used for multiple sequence alignment, the phylogenetic trees constructed by the neighbor-joining method were verified by bootstrap.

\subsection{Statistical Analysis}

The data of the effects of heat stress on the expression of $P x$-fng and Px-en in DBM, the survival rate and gene expression level of the DBM when injected with dsRNA were analyzed by the Statistical 
Product and Service Solutions (SPSS21, IBM, Armonk, USA) software. Duncan's test was used for the analysis of the difference among the multiple group of samples.

\section{Results}

\subsection{Cloning and Sequences Analysis of Px-fng and Px-en}

Based on the $3^{\prime}$ - and 5'-RACE amplification fragments and first cDNA fragments, the full-length cDNA of Px-fng and Px-en were cloned, with the NCBI GenBank numbers MK530647 and MK530646, respectively. The full-length of $P x$-fng was $2140 \mathrm{bp}$ and $P x$-en was $2361 \mathrm{bp}$, and the open reading frame (ORF) sequences were 1038 bp for $P x$-fng and 1152 bp for Px-en, respectively. The $P x$-fng encodes 345 amino acids. Moreover, it also has a transmembrane helix region(7aa-26aa) and a Fringe functional domain (80 aa-328 aa). ExPASy analysis deduced a molecular weight of 39.59 KDa and predicted an isoelectric point of 8.01 . The $P x$-en encodes 383 amino acids. In addition, it contains a HOX domain from 297 aa to 359 aa. ExPASy analysis deduced a molecular weight of $42.69 \mathrm{KDa}$ and predicted an isoelectric point of 9.31. According to the Blast results, the obtained $P x$-fng and $P x$-enamino acid sequences of DBM were consistent with that of other insects, for Px-fng, 57\% identity with Danaus plexippus (OWR44193.1), 59\% with Helicoverpa armigera (XP_02 118354 9.1), 54\% with B. mori (NP_001116813.1), 57\% with Junonia coenia (AAO38754.1), and 42\% with Drosophila erecta (XP_001973555.1) (Figure 1); for Px-en, 76\% with $H$. armigera (XP_021180829.1), 77\% with Spodopteralitura (XP_022817253.1), 73\% with B. mori (NP_001037550.2), 73\% with Papilio Dardanus (CAX36786.1), 72\% with Bicyclusanynana (XP_023948032.1), and 32\% with Drosophila melanogaster (BAN82731.1) (Figure 2). Phylogenetic analysis showed that Px-fng and Px-en were clustered together with the fringe and engrailed proteins in other Lepidoptera insects, and formed independent populations in the phylogenetic trees with their homologs, brainiac and infected, respectively (Figures S1 and S2).
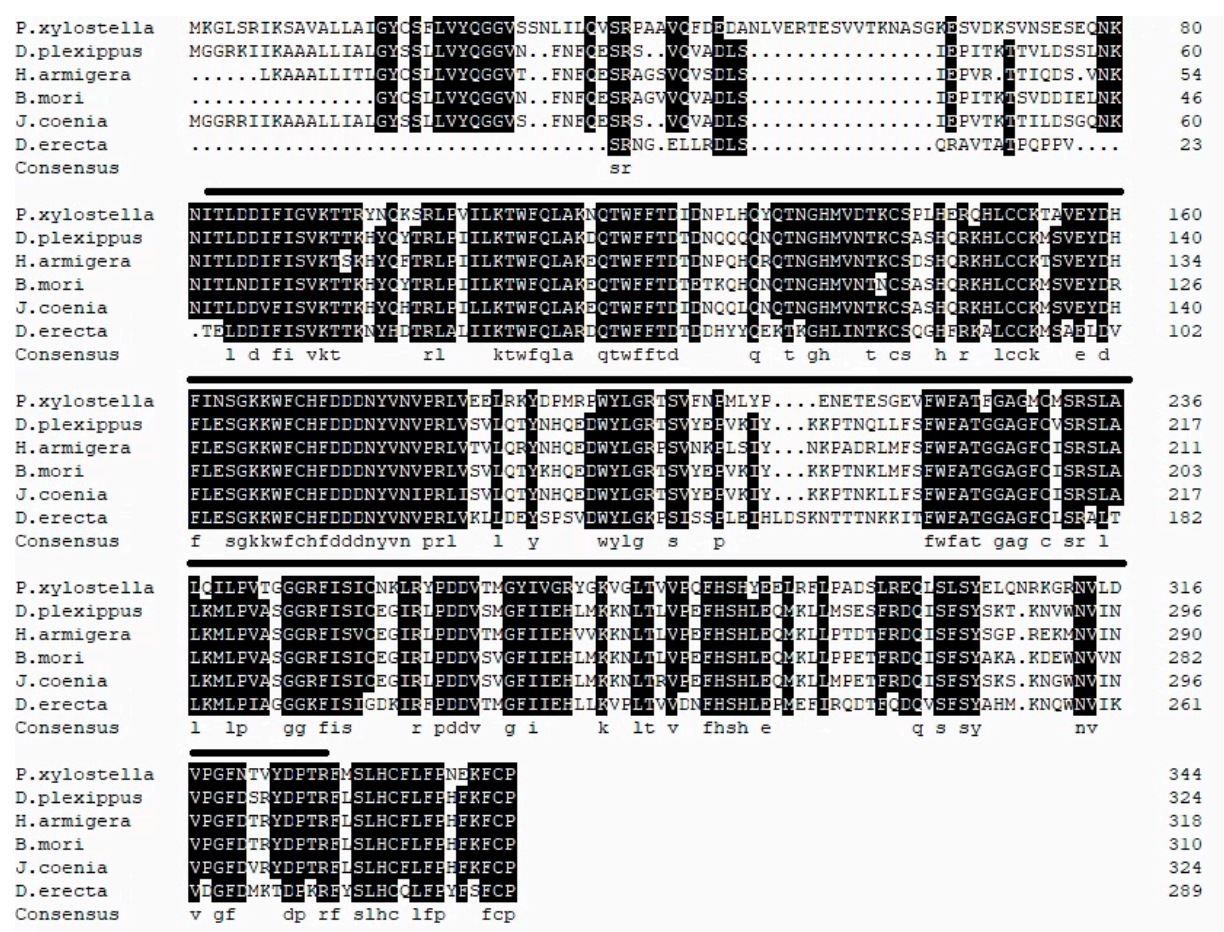

Figure 1. Multiple alignments of Px-fng. The amino acids labeled below represented identical residues in all the species. Lines above the sequences defined the conserved domain of Fringe. The GenBank number of the sequences were: P. xylostella (MK530647.1), D. plexippus (OWR44193.1), H. armigera (XP_021183549.1), B. mori (NP_001116813.1), J. coenia (AAO38754.1), and D. erecta (XP_001973555.1). 


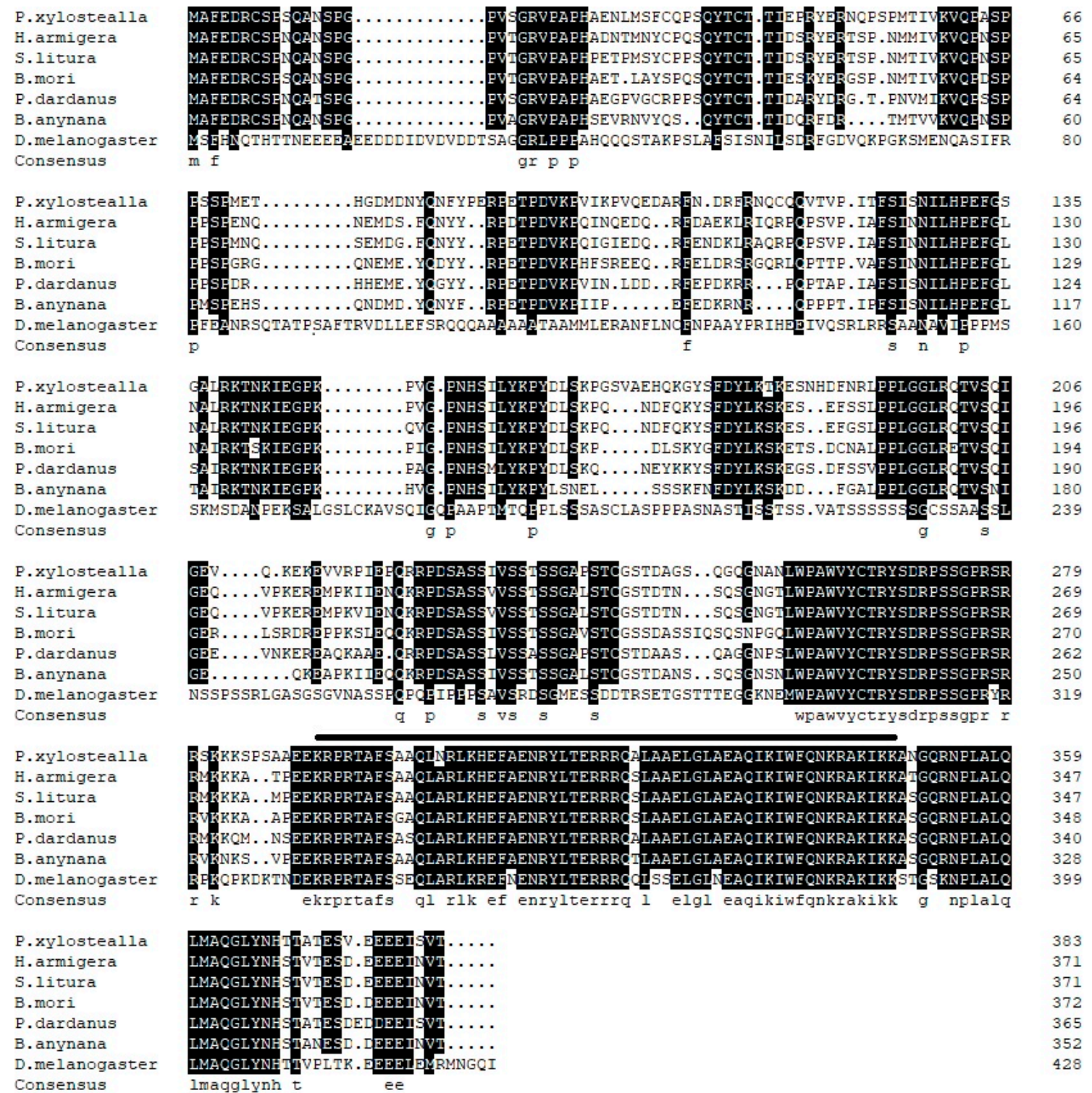

Figure 2. Multiple alignments of Px-En. The amino acids labeled below represented identical residues in all the species. Lines above the sequences defined the conserved domain of Engrailed. The GenBank number of the sequences were: P. xylostella (MK530646.1), H. armigera (XP_021180829.1), S. litura (XP_022817253.1), B. mori (NP_001037550.2), P. dardanus (CAX36786.1), B. anynana (XP_023948032.1), and D. melanogaster (BAN82731.1).

\subsection{Expressions of Px-fng and Px-en under Heat Stresses in Pupae and Adults}

The mRNA expression of $P x$-fng and $P x$-en in pupae or adults of Rc- and Sm-DBM under heat stress showed that: the basal levels (at $25^{\circ} \mathrm{C}$ ) of $P x$-fng and $P x$-en expression were high in adults or pupae of both Rc- and Sm-DBM, however, there was no significant difference between Rc- and Sm-DBM. In the group of $25^{\circ} \mathrm{C}$ for $48 \mathrm{~h}$ and $38^{\circ} \mathrm{C}$ for $48 \mathrm{~h}$, the expression of $P x$-fng and $P x$-en in adults and pupae were significantly downregulated under heat stress $\left(38^{\circ} \mathrm{C}\right)$ than the basal level $\left(25^{\circ} \mathrm{C}\right)$ in both Rc- and Sm-DBM, but the downregulation degree of Rc-DBM was more obvious. The same phenomenon under heat stress expression were also be found in $40^{\circ} \mathrm{C}, 8 \mathrm{~h} ; 40{ }^{\circ} \mathrm{C}, 16 \mathrm{~h} ; 42^{\circ} \mathrm{C}, 4 \mathrm{~h}$; $42{ }^{\circ} \mathrm{C}, 8 \mathrm{~h}$ and $44{ }^{\circ} \mathrm{C}, 1 \mathrm{~h}$ when compared with $25^{\circ} \mathrm{C}$ (Figure 3 ). 

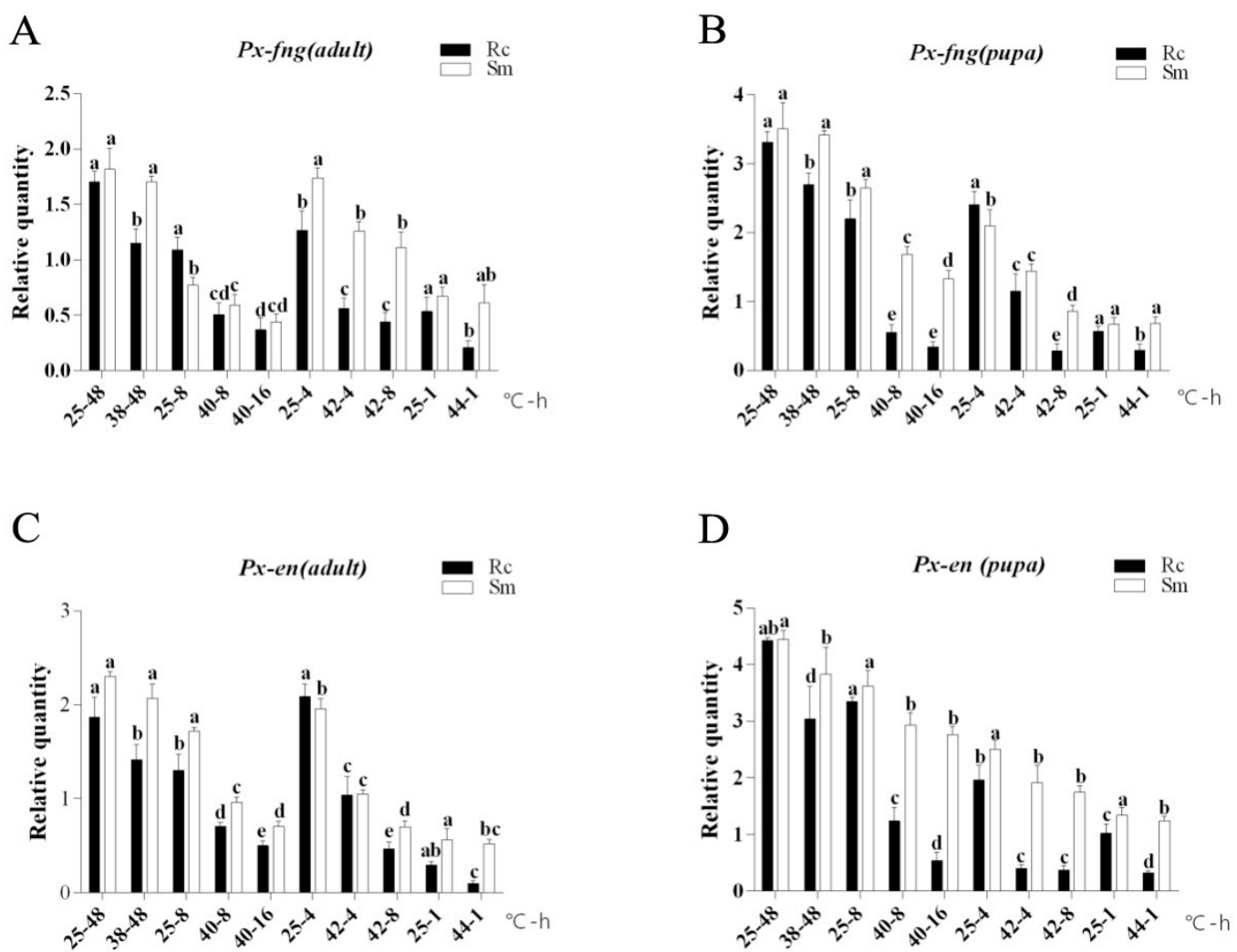

Figure 3. Different heat stress on the expression of $P x$-fng and $P x$-en in DBM. Rc: insecticide-resistant DBM, Sm: insecticide-susceptible DBM. Abscissa: temperature $\left({ }^{\circ} \mathrm{C}\right)$-treated time (h). Ordinate: the relative transcription expression (Mean \pm SE) of $P x-f n g$ and $P x-e n$, respectively. (A): Effects of heat stress on the expression of $P x-f n g$ in adult DBM. (B): Effects of heat stress on the expression of $P x-f n g$ in pupa DBM. (C): Effects of heat stress on the expression of Px-en in adult DBM. (D): Effects of heat stress on the expression of $P x$-en in pupa DBM. Duncan's test was used for the analysis of the difference between different groups of samples. According to the four groups of experiments designed above (different temperature treatment), each group was analyzed separately, and then these data were integrated into one figure. Therefore, different lowercase letters in the figures represent the statistically significant difference (Duncan's test, $p \leq 0.05$ ) between each sample in the corresponding groups, and the same letter means that there is no significant difference.

\subsection{Px-fng and Px-en Expression in Response to dsRNA in DBM Wings}

In order to determine the most suitable doses of dsRNA and the observation time of interference, different doses of dsRNA were used to inject the DBM, and the results suggest that $138 \mathrm{nl}$ dsRNA can achieve the best interference effect while maintaining a sufficient survival rate (Table 4, Figures 4 and 5). After injection of dsFng or dsEn, among 210 pupae, the emergency rate of pupae was $72 \%$ or $73 \%$, respectively, and the wing deformity rate was $37.75 \%$ or $40.52 \%$, respectively. However, after injection of dsGFP and $\mathrm{ds}_{2} \mathrm{O}$, the emergency rate of pupae was as high as $94 \%$ or $91 \%$, respectively, and no wing damage was found (Table 4, Figures 4 and 5). Wing damage usually manifests itself as a loss of one or more veins of the hind wing. After the injection of dsFng or dsEn into the pupae, in addition to the $\mathrm{Rp}$ vein loss, $\mathrm{Mb}, \mathrm{m}$ and $\mathrm{m}$-c were also weakened, although not as obvious as $\mathrm{Rp}$ [6]. Compared to the control group (injected with dsGFP), the expression of $P x$-fng and $P x$-en was significantly suppressed in both $\mathrm{Sm}$-and Rc-pupae at $4 \mathrm{~h}, 8 \mathrm{~h}$, and $16 \mathrm{~h}$ after being injected with dsFng and dsEn (Figure 6). However, no significant inhibitions on the expression of $P x$-fng and $P x$-en were found in Sm- or Rc-pupae 48h after being injected with dsFng and dsEn (Figure 6). 


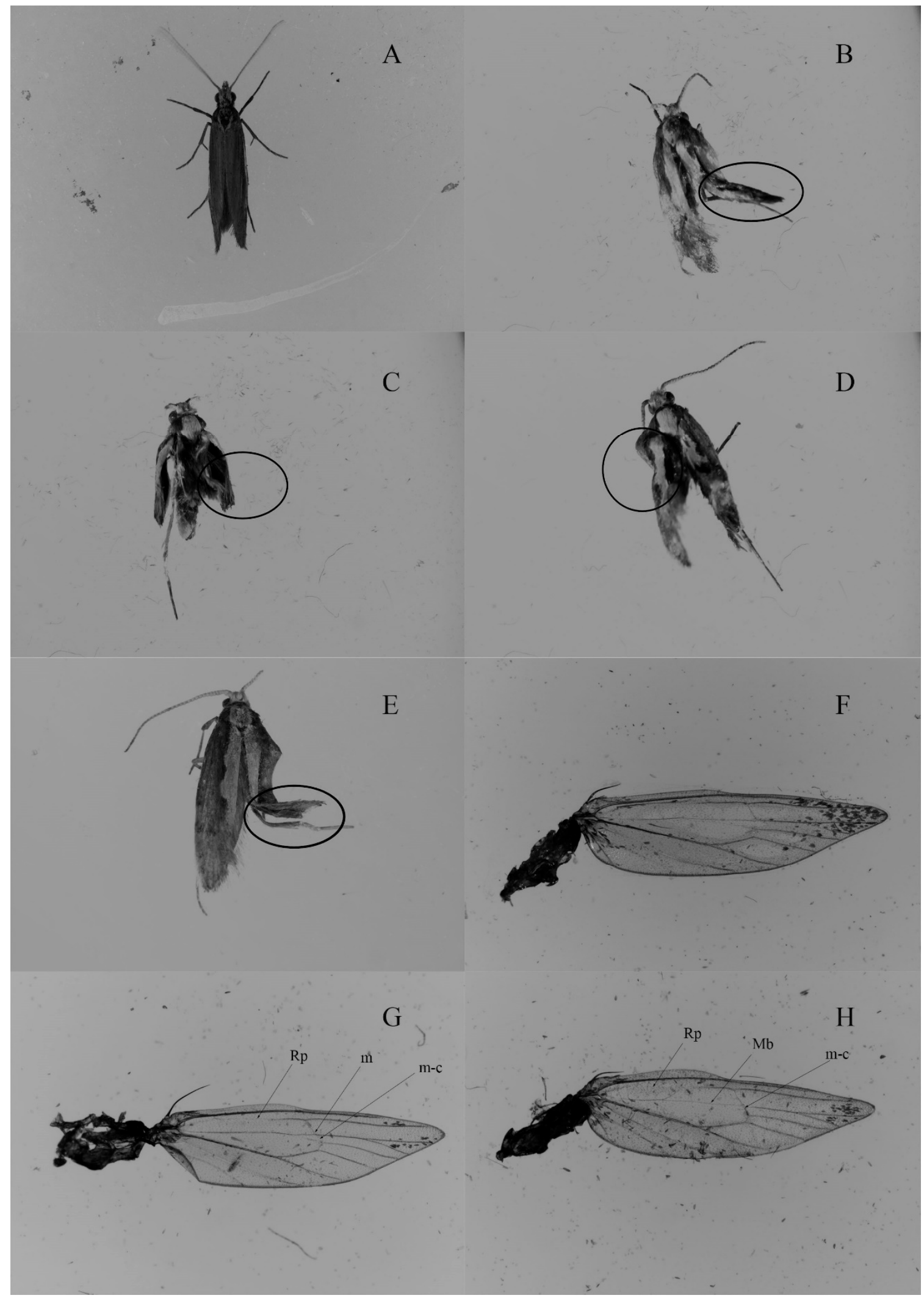

Figure 4. Normal and wing deformity in DBM adults. (A) Normal adult. (B,C) Wings with phenotypic changes after treatment with dsFng. (D,E) Wings with phenotypic changes after treatment with dsEn. (F) Wing with normal veins. (G,H) Wings with the vein missing or weakening (indicated by an arrow) after the injection of dsFng and dsEn, respectively, Rp: Radinus posterior, m: Medial crossvein, m-c: Medialcubitus crossvein, Mb: Medial bar. 
A

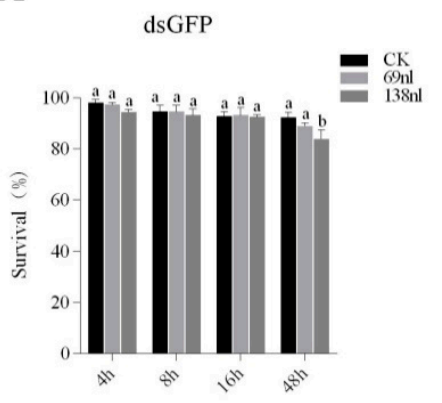

B

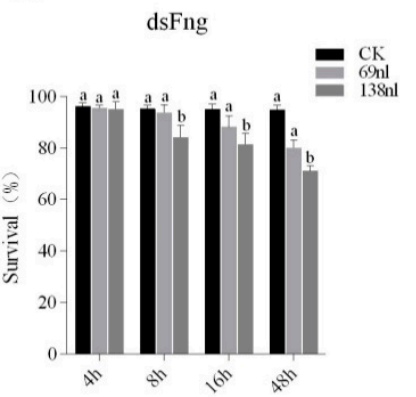

$\mathrm{C}$

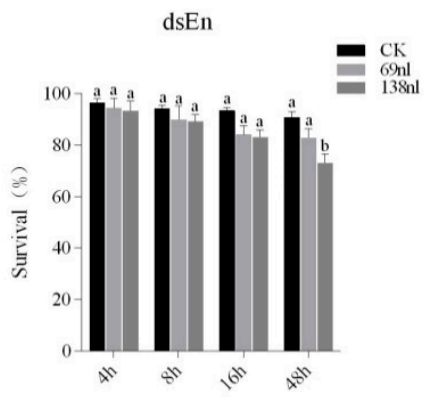

Figure 5. The survival (\%) of the pupae of DBM when injected with different doses of dsFng, dsEn, and dsGFP. A total of $138 \mathrm{nl}$ dsRNA ( $2 \mu \mathrm{g} / \mu \mathrm{L})$ was selected for RNAi as it can achieve the best interference effect while maintaining a sufficient survival rate (more than 70 percent). (A): The survival (\%) of the pupae of DBM when injected with different doses of dsGFP, (B): The survival (\%) of the pupae of DBM when injected with different doses of dsFng, (C): The survival (\%) of the pupae of DBM when injected with different doses of dsEn. Data in the figures were represented by mean $\pm \mathrm{SE}$, and the Duncan's test was used for the analysis of the difference in each treatment. The different lowercase letters indicate significant differences (Duncan's test, $p \leq 0.05$ ) in each sample under different treatments at each time point, respectively.

A

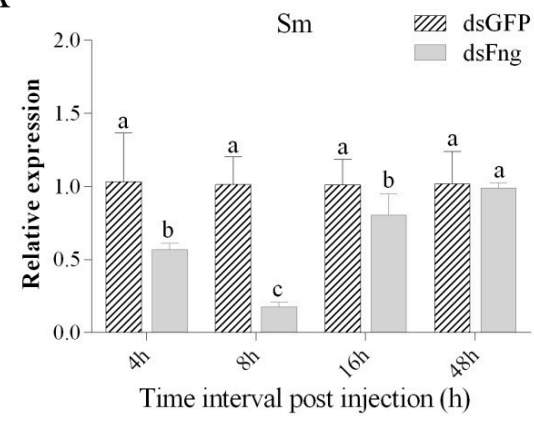

$\mathrm{C}$

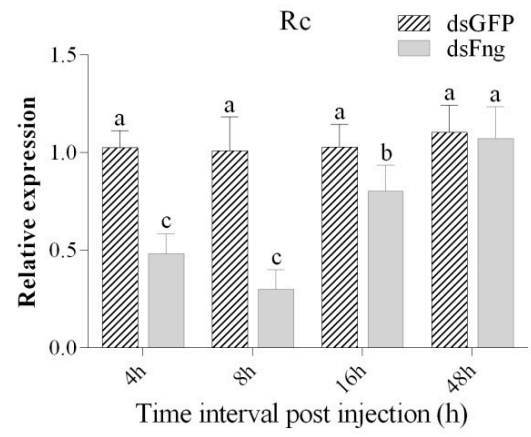

B

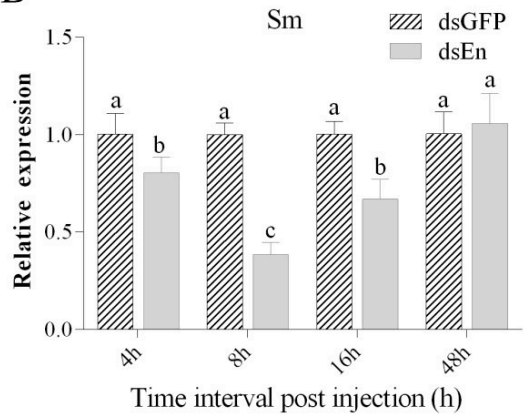

D

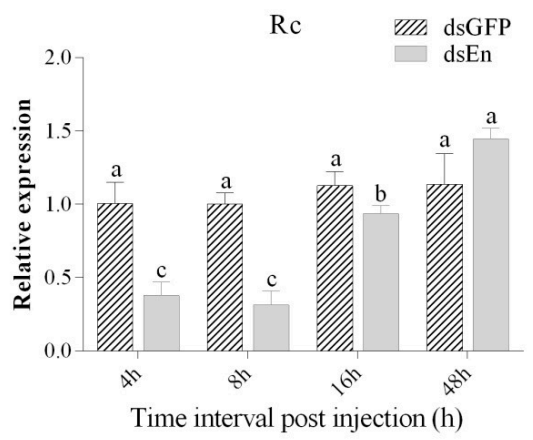

Figure 6. Comparison of $P x-f n g$ and $P x$-en expression levels in Rc-and Sm-pupae by dsFng or dsEn at different times after treatment. (A): $P x$-fng expression in Sm-pupae by dsFng treatment, (B): $P x$-en expression in Sm-pupae by dsEn treatment, (C): Px-fng expression in Rc-pupae by dsFng treatment, (D): Px-en expression in Rc-pupae by dsEn treatment. Duncan's test was used for the analysis of the difference among different groups of samples. Different lowercase letters indicate significant differences in each sample (both Rc and Sm) at different time point after RNA interference (Duncan's test, $p \leq 0.05$ ). The $\mathrm{x}$-axis indicates the time interval post injection. 


\section{Discussion}

In the present study, two cDNA sequences from the DBM were identified and characterized. From the amino acid analysis, we determined that Px-fng and Px-en proteins of DBM had a high conserved region compared to other species. Furthermore, the phylogenetic analysis confirmed that both the Px-fng and Px-en with other Lepidopteran insects had the closest genetic relationship. The above analysis also supports the fact that the cloned sequences were our target genes.

According to previous research results, among the wing-development-related genes, the mRNA expression of those genes was significantly downregulated in Rc-DBM compared to Sm-DBM under heat stress [37]. In our present study, for the pupae or adults, the expression of both $P x$-fng and $P x$-en declined under heat stress. The Rc-strain showed more significant downregulation in mRNA expression than Sm under heat stress. It is speculated that, to some extent, this phenomenon is related to the fact that the damage degree of Rc-DBM wing veins are higher than that of Sm-DBM under thermal stress [6].

Temperature is an important climatic factor, which can affect the ecological and evolutionary processes of organisms. In recent years, with global warming, the effect of temperature on insect fitness has become the focus of research. Heat stress is also deleterious to fitness costs [40]. Particularly in insects, there have been many reports, for example, Xestia c-nigrum (Lepidoptera: noctuidae) showed delayed development [41] and Trichogrammacarverae reduced its parasitic rate [42]. In our previous study, different temperature treatments can affect the fitness cost of Rc- and Sm-DBM. The Sm-strain is more suitable for high temperatures than the Rc-strain [6]. In this study, Px-fng and Px-enin Rc-DBM under heat stress had significantly downregulated expression compared to Sm-pupae. As the $P x-f n g$ and $P x$-en expressions were inhibited after an injection of dsFng and dsEn, a deformity of veins occurred (Figures 4-6). It was speculated that these two genes might be involved in the developments of vines. In addition, it should be noted that, in our present study, $P x$-fng and $P x$-en were confirmed to be involved in the development of the wings in DBM based on dsRNA. However, aside from malformation and vein damage, wide-spread phenotypes (Figure 4) such as the effects on other tissues including the body, antenna, and leg, were observed in RNAi treatments, which implicated that $P x$-fng and $P x$-en might be involved in the development of many tissues throughout the body of DBM. In Drosophila, both engrailed and fringe were confirmed to be expressed in many tissues throughout the body $[14,18]$. In our experiment, we injected dsRNA into the pupae, which showed non-specificity to the wing, but led to many other tissue malformations. Nevertheless, our study established a relationship between these two genes (Px-fng and $P x-e n)$ and the development of the wings of DBM for the first time. However, their specific regulatory mechanisms still need to be further studied in the future such as studying the specific expression regulation of their wings to find out their effects on wing development.

In this study, only Rc-DBM was used to study the effects of RNA interference on wing deformity and wing damage (Table 4 and Figure 4), although the comparisons of the effects of RNA interference on Px-fng and Px-en expression between Rc- and Sm-DBM were carried out (Figure 6). However, compared to Sm-DBM, higher vein damage in Rc-DBM under heat stress was confirmed in our previous study [6]. In the present study, $P x$-fng and $P x$-en were first confirmed to be involved in the development of wings and veins based on RNAi experiments. Our results also confirmed that the inhibition of heat stress on the expression of two genes of Rc is significantly greater than Sm. Thus, we proposed that the more severe damage of Rc venation compared to Sm under heat stress may be related to the more serious inhibition of $P x$-fng and $P x$-en. However, it is important to pay attention to the absence of the vein after RNAi, which was mainly concentrated in Rp in this study. In addition, $\mathrm{Mb}, \mathrm{m}$, and $\mathrm{m}-\mathrm{c}$ were also weakened, but not as obviously as Rp. In our previous studies, the absence of the vein caused by heat stress occurred mainly in $\mathrm{Mb}, \mathrm{m}, \mathrm{m}-\mathrm{c}$, and r-m [6], which indicated that the use of RNAi and a heat stress treatment would both lead to the absence of the vein, but the results were not the same, suggesting that there is something different between the mechanisms of heat stress and RNAi on the development of a vein. Heat stress leads to changes in the expression of multiple genes including $P x$-fng and $P x$-en, but $P x$-fng and $P x$-en may be the key genes in the developmental path of 
DBM venation. The inhibition of these two genes by RNAi may also affect the expression of multiple genes related to this path. Therefore, RNAi and heat stress lead to the deletion of venation, which may be influenced by both common genes and their own specific gene expression. As for RNAi and heat stress, it is necessary to further study the mechanism in the absence of the vein, respectively.

\section{Conclusions}

Our results suggest that heat stress downregulated the wing development genes $P x$-fng and $P x$-en, thus resulting in damage to wing veins and fitness cost in the Rc-DBM strains. The fitness cost in Rc-DBM in the previous studies [6,33-35] and the current study might be related to the alleles ace1R which mediates the resistance of many organophosphorus pesticides [34,35]. However, this hypothesis still needs further verification. The study of the cost of resistance fitness of DBM from the perspective of a morphological difference under heat stress is an innovative topic in this field. It will be helpful to clarify the sharp decline of the resistance level of DBM during the high temperature period of summer in the field, which will help to further study the physiological response, heredity, and the evolution of insects under environmental stress. In the case of global warming, our research on the influence of temperature on the resistance level of DBM has important guiding significance for the control of DBM in the field.

Supplementary Materials: The following are available online at http://www.mdpi.com/2075-4450/11/5/287/s1, Figure S1: Phylogenetic tree of fringe in different species of insects, Figure S2: Phylogenetic tree of engrailed in different species of insects.

Author Contributions: G.W. conceived the experiments, analyzed the data, generated the tables, produced the figures, wrote and edited the manuscript; Y.W., J.W., and G.W. performed the experiments; X.X. conceived the experiments, analyzed the data, wrote, and edited the manuscript. All authors have read and agreed to the published version of the manuscript.

Funding: This research was funded by the National Natural Science Foundation of China (NNSFC) (31272049) and Key Foundation of Technology Project of Fujian Province (2014N0003).

Acknowledgments: This study was financially supported by the National Natural Science Foundation of China (NNSFC) (31272049) and the Key Foundation of Technology Project of Fujian Province (2014N0003).

Conflicts of Interest: The authors declare no conflicts of interest.

\section{References}

1. Wootton, R.J. Functional morphology of insect wings. Annu. Rev. Entomol. 1992, 37, 113-140. [CrossRef]

2. Weatherbee, S.D.; Halder, G.; Kim, J.; Hudson, A.; Carroll, S. Ultrabithorax regulates genes at several levels of the wing-patterning hierarchy to shape the development of the Drosophila haltere. Genes Dev. 1998, 12, 1474-1482. [CrossRef]

3. Posakony, L.G.; Raftery, L.A.; Gelbart, W.M. Wing formation in Drosophila melanogaster requires decapentaplegic gene function along the anterior-posterior compartment boundary. Mech. Dev. 1990, 33, 69-82. [CrossRef]

4. Klein, T.; Arias, A.M. Different spatial and temporal interactions between Notch, wingless, and vestigial specify proximal and distal pattern elements of the wing in Drosophila. Dev. Biol. 1998, 194, 196-212. [CrossRef] [PubMed]

5. Debat, V.; Debelle, A.; Dworkin, I. Plasticity, canalization, and developmental stability of the Drosophila wing: Joint effects of mutations and developmental temperature. Evolution 2009, 63, 1558-5646. [CrossRef] [PubMed]

6. Zhang, L.J.; Wu, Z.L.; Wang, K.F.; Liu, Q.; Zhuang, H.M.; Wu, G. Trade-off between thermal tolerance and insecticide resistance in Plutella xylostella. Ecol. Evol. 2015, 5, 515-530. [CrossRef] [PubMed]

7. Lewis, E.B. A gene complex controlling segmentation in drosophila. Nature 1978, 276, 565-570. [CrossRef] [PubMed]

8. Campbell, G.; Tomlinson, A. The roles of the homeobox genes aristaless and distal-less in patterning the legs and wings of Drosophila. Development 1998, 125, 4483-4493. 
9. Celis, J.F.D. Pattern formation in the Drosophila wing: The development of the veins. BioEssays 2003, 25, 443-451. [CrossRef]

10. Maschat, F.; Serrano, N.; Randsholt, N.B.; Geraud, G. Engrailed and polyhomeotic interactions are required to maintain the a/p boundary of the Drosophila developing wing. Development 1998, 125, 2771-2780.

11. Guillén, I.; Mullor, J.L.; Capdevila, J.; Sánchez-Herrero, E.; Guerrero, I. The function of engrailed and the specification of Drosophila wing pattern. Development 1995, 121, 3447-3456. [PubMed]

12. Lawrence, P.A.; Morata, G. Compartments in the wing of Drosophila: A study of the engrailed gene. Dev. Biol. 1976, 50, 321-337. [CrossRef]

13. Kornberg, T. Engrailed: A gene controlling compartment and segment formation in Drosophila. Proc. Natl. Acad. Sci. USA 1981, 78, 1095-1099. [CrossRef]

14. Peltenburg, L.T.; Murre, C. Engrailed and hox homeo domain proteins contain a related pbx interaction motif that recognizes a common structure present in pbx. EMBO J. 1996, 15, 3385-3393. [CrossRef]

15. Bourbon, H.M.; Martinblanco, E.; Rosen, D.; Kornberg, T.B. Phosphorylation of the Drosophila engrailed protein at a site outside its homeodomain enhances DNA binding. J. Biol. Chem. 1995, 270, 11130-11139. [CrossRef]

16. Brunetti, C.R.; Selegue, J.E.; Monteiro, A.; French, V.; Brakefield, P.M.; Carroll, S.B. The generation and diversification of butterfly eyespot color patterns. Curr. Biol. Cb 2001, 11, 1578-1585. [CrossRef]

17. Irvine, K.D.; Wieschaus, E. fringe, a boundary-specific signaling molecule, mediates interactions between dorsal and ventral cells during Drosophila wing development. Cell 1994, 79, 95-606. [CrossRef]

18. Munro, S.; Freeman, M. The notch signalling regulator fringe acts in the golgi apparatus and requires the glycosyltransferase signature motif DxD. Curr. Biol. 2000, 10, 813-820. [CrossRef]

19. Irvine, K.D.; Rauskolb, C. Boundaries in development: Formation and function. Annu. Rev. Cell Dev. Biol. 2001, 17, 189-214. [CrossRef]

20. Correia, T.; Papayannopoulos, V.; Panin, V.; Woronoff, P.; Jiang, J.; Vogt, T.F.; Irvine, K.D. Molecular genetic analysis of the glycosyltransferase fringe in Drosophila. Proc. Natl. Acad. Sci. USA 2003, 100, 6404-6409. [CrossRef]

21. Xu, G.; Zhang, J.; Lyu, H.; Liu, J.; Ding, Y.; Feng, Q.; Song, Q.; Zheng, S. BmCHSA-2b, a, Lepidoptera, specific alternative splicing variant of epidermal chitin synthase, is required for pupal wing development in Bombyx mori. Insect Biochem. Mol. Biol. 2017, 87, 117-126. [CrossRef] [PubMed]

22. Zhang, J.; Xu, G.; Qiu, B.; Zhang, X.; Feng, Q.; Yang, Q.; Zheng, S. BR-CZ4 and FoxJ interact to regulate expression of a chitin synthase gene CHSA-2b in the pupal wing discs of the silkworm, Bombyx mori. Insect Biochem. Mol. Biol. 2020, 116, 103264. [CrossRef] [PubMed]

23. Yang, W.J.; Xu, K.K.; Yan, X.; Li, C. Knockdown of $\beta-N$-acetylglucosaminidase 2 Impairs Molting and Wing Development in Lasioderma serricorne (Fabricius). Insects 2019, 10, 396. [CrossRef] [PubMed]

24. Li, X.; Liu, F.; Wu, C.; Zhao, J.; Cai, W.; Hua, H. Decapentaplegic function in wing vein development and wing morph transformation in brown planthopper, Nilaparvata lugens. Dev. Biol. 2019, 449, 143-150. [CrossRef]

25. Crozatier, M.; Glise, B.; Vincent, A. Patterns in evolution: Veins of the Drosophila wing. Trends Genet. 2004, 20, 498-505. [CrossRef]

26. Shimmi, O.; Matsuda, S.; Hatakeyama, M. Insights into the molecular mechanisms underlying diversified wing venation among insects. Proc. R. Soc. B Biol. Sci. 2014, 281, 20140264. [CrossRef]

27. Huang, Y.; Hatakeyama, M.; Shimmi, O. Wing vein development in the sawfly Athalia rosae is regulated by spatial transcription of Dpp/BMP signaling components. Arthropod Struct. Dev. 2018, 47, 408-415. [CrossRef]

28. Matsuda, S.; Yoshiyama, N.; Künnapuu-Vulli, J.; Hatakeyama, M.; Shimmi, O. Dpp/BMP transport mechanism is required for wing venation in the sawfly Athalia rosae. Insect Biochem. Mol. Biol. 2013,43, 466-473. [CrossRef]

29. Baxter, S.W.; Zhao, J.Z.; Gahan, L.J.; Shelton, A.M.; Tabashnik, B.E.; Heckel, D.G. Novel genetic basis of field-evolved resistance to Bt toxins in Plutella xylostella. Insect Mol. Biol. 2005, 14, 327-334. [CrossRef]

30. You, M.; Yue, Z.; He, W.; Yang, X.; Yang, G.; Xie, M.; Zhan, D.; Baxter, S.W.; Vasseur, L.; Gurr, G.M.; et al. A heterozygous moth genome provides insights into herbivory and detoxification. Nat. Genet. 2013, 45, 220-225. [CrossRef]

31. Talekar, N.S.; Shelton, A.M. Biology, ecology, and management of the diamondback moth. Annu. Rev. Entomol. 1993, 38, 275-301. [CrossRef] 
32. Zalucki, M.P.; Shabbir, A.; Silva, R.; Adamson, D.; Shu-Sheng, L.; Furlong, M.J. Estimating the economic cost of one of the world's major insect pests, Plutella xylostella (Lepidoptera: Plutellidae): Just how long is a piece of string? J. Econ. Entomol. 2012, 105, 1115-1129. [CrossRef] [PubMed]

33. Zhang, L.J.; Wang, K.F.; Jing, Y.P.; Zhuang, H.M.; Wu, G. Identification of heat shock protein genes $h s p 70 s$ and $h s c 70$ and their associated mRNA expression under heat stress in insecticide-resistant and susceptible diamondback moth, Plutella xylostella (Lepidoptera: Plutellidae). Eur. J. Entomol. 2015, 112, 215-226. [CrossRef]

34. Zhang, L.J.; Jing, Y.P.; Li, X.H.; Li, C.W.; Bourguet, D.; Wu, G. Temperature-sensitive fitness cost of insecticide resistance in Chinese populations of the diamondback moth Plutella xylostella. Mol. Ecol. 2015, 24, 1611-1627. [CrossRef]

35. Zhang, L.J.; Chen, J.L.; Yang, B.L.; Kong, X.G.; Bourguet, D.; Wu, G. Thermotolerance, oxidative stress, apoptosis, heat-shock proteins and damages to reproductive cells of insecticide-susceptible and -resistant strains of the diamondback moth Plutella Xylostella. Bull. Entomol. Res. 2017, 107, 513-526. [CrossRef]

36. Gassmann, A.J.; Carriere, Y.; Tabashnik, B.E. Fitness costs of insect resistance to Bacillus thuringiensis. Annu. Rev. Entomol. 2019, 54, 147-163. [CrossRef]

37. Chen, X.Z.; Hu, Q.X.; Liu, Q.Q.; Wu, G. Cloning of wing-development-related genes and mRNA expression under heat stress in chlorpyrifos-resistant and -susceptible Plutella xylostella. Sci. Rep. 2018, 8, 1-11. [CrossRef]

38. Shi, X.Z.; Guo, Z.J.; Zhu, X.; Wang, S.L.; Xu, B.Y.; Xie, W.; Zhang, Y.J.; Wu, Q.J. RNA interference of the inhibitory glutamate receptor in Plutella xylostella (lepidoptera: Plutellidae). Acta Entomol. Sin. 2012, 55, 1331-1336.

39. Tamura, K.; Stecher, G.; Peterson, D.; Filipski, A.; Kumar, S. MEGA6: Molecular Evolutionary Genetics Analysis version 6.0. Mol. Biol. Evol. 2013, 30, 2725-2729. [CrossRef]

40. Maclean, H.J.; Kristensen, T.N.; Overgaard, J.; Sørensen, G.J.; Bahrndorff, S. Acclimation responses to short-term temperature treatments during early life stages causes long lasting changes in spontaneous activity of adult Drosophila melanogaster. Physiol. Entomol. 2017, 42, 404-411. [CrossRef]

41. Wang, L.; Yang, S.; Han, L.; Zhao, K.; Ye, L. Expression profile of two HSP70 chaperone proteins in response to extreme thermal acclimation in Xestia c-nigrum (Lepidoptera: Noctuidae). Fla. Entomol. 2015, 98, 506-515. [CrossRef]

42. Scott, M.; Berrigan, D.; Hoffmann, A.A. Costs and benefits of acclimation to elevated temperature in Trichogramma carverae. Entomol. Exp. Appl. 1997, 85, 211-219. [CrossRef] 